\title{
Autonomia do graduando em enfermagem na (re)construção do conhecimento mediado pela aprendizagem baseada em problemas
}

\author{
Autonomy of nursing undergraduate student in the (re)construction of knowledge \\ mediated by problem-based learning \\ La autonomía del estudiante de enfermería en la (re)construcción del conocimiento \\ mediada por el aprendizaje basado en problemas
}

\begin{abstract}
Leonara Raddai Gunther de Campos', Mara Regina Rosa Ribeiro', Valéria Binato Santili Depes"
' Universidade Federal de Mato Grosso, Faculdade de Enfermagem, Programa de Pós-Graduação em Enfermagem. Cuiabá-MT, Brasil.

"Secretaria de Estado de Saúde de Mato Grosso, Escola de Saúde Pública do Estado de Mato Grosso. Cuiabá-MT, Brasil.
\end{abstract}

Submissão: 31-07-2013 Aprovação: 31-07-2014

\section{RESUMO}

Estudo qualitativo, método Bricolagem, que objetivou analisar como a Aprendizagem Baseada em Problemas (ABP) promove o desenvolvimento da autonomia do aluno no processo de aprender a aprender. Os sujeitos foram 16 alunos e dois tutores envolvidos na disciplina. A coleta dos dados combinou entrevista semiestruturada, observação participante, registro em portfólios, fichas de avaliação, e gravação em áudio das tutorias. A análise dos dados seguiu estratégias de interpretação definidas pelas autoras: leituras iniciais e aprofundada; construção e reunião de mapas de significados; elaboração, descrição e análise de categorias empíricas, à luz do referencial teórico. A ABP favorece a (re)construção de conhecimentos pela utilização de saberes e experiências prévias, que são compartilhados no pequeno grupo; pelo processo de teorização; e pela via do conhecimento pertinente - aquele passível de aplicação à prática. Concluímos que a ABP estimula o aprendizado contínuo, desenvolvendo no aluno autonomia no processo de aprender a aprender.

Descritores: Educação Superior; Prática do Docente de Enfermagem; Aprendizagem Baseada em Problemas.

ABSTRACT
This is a qualitative study, using the 'Do it yourself' method, which aimed to analyze how Problem-Based Learning (PBL) promotes the development of learner's autonomy in the process of learning to learn. The subjects were 16 students and two tutors involved in the discipline. Data collection techniques combined semi-structured interviews, participant observation, log in portfolios, evaluation forms, and audio recording of the tutorials. Data analysis followed interpretation strategies defined by the authors: initial and in depth readings; construction and assembly of meanings' maps; development, description and analysis of empirical categories, in the light of the theoretical framework. The PBL favors the (re)construction of knowledge by the use of prior knowledge and experiences that are shared in small group; through the process of theorization; and by means of relevant knowledge - one that can be applied to practice. We conclude that PBL encourages continuous learning, developing in the student the autonomy in the process of learning to learn.

Key words: Education, Higher; Nursing Faculty Practice; Problem-Based Learning.

\section{RESUMEN}

Estudio cualitativo, con método Bricolage, que tuvo como objetivo analizar cómo el Aprendizaje Basado en Problemas (ABP) promueve el desarrollo de la autonomía del alumno en el proceso de aprender a aprender. Los sujetos fueron 16 alumnos y dos tutores que participan en la disciplina. Para recolección de datos se combinaran entrevistas estructuradas, observación participante, registro en portfolios, formularios de evaluación y grabación de audio de los tutoriales. El análisis de los datos siguió las estrategias de interpretación definidos por los autores: lecturas iniciales y profundadas; construcción y montaje de mapas de significados; el desarrollo, descripción y análisis de categorías empíricas, a la luz de lo referencial teórico. El ABP favorece la construcción de conocimientos mediante el uso de saberes y experiencias que se comparten en grupos pequeños, a través del proceso de teorización, y por medio de los conocimientos pertinentes - uno que se puede aplicar a la práctica. Llegamos a la conclusión que el ABP promueve el aprendizaje continuo, el desarrollo de los estudiantes, la autonomía en el proceso de aprender a aprender.

Palabras clave: Educación Superior; Práctica del Docente de Enfermería; Aprendizaje Basado en Problemas. 


\section{INTRODUÇÃO}

Atualmente, a formação em enfermagem vem sendo solicitada a responder ao desafio de formar profissionais competentes para o trabalho em saúde ${ }^{(1)}$. A necessidade de mudanças é assumidamente comprovada, dada a ineficácia do modelo tradicional e compartimentalizado de ensino, frente à capacidade de resposta às demandas sociais ${ }^{(2)}$.

Assim, as metodologias ativas invadem o cenário tradicional de ensino propondo o protagonismo do aluno no processo de aprendizagem, com vistas a viabilizar o desenvolvimento de sua autonomia ${ }^{(3)}$. A autonomia do enfermeiro é indispensável para o exercício de suas atividades durante a prática profissional, portanto, precisa ser estimulada desde os primeiros momentos de formação do aluno durante o período de graduação.

A Aprendizagem Baseada em Problemas (ABP) é uma das metodologias ativas mais difundidas em cursos de saúde e enfermagem, firmando sua base teórica no princípio da autono$\mathrm{mia}^{(3-5)}$. Ela reconhece a "necessidade de formar enfermeiros competentes nas dimensões técnica, científica, ética e política", ou seja, "sujeitos sociais com capacidade de atuar em contextos de incertezas e complexidade" ${ }^{\prime(3)}$. Seu intuito é proporcionar uma aprendizagem significativa, aproximando os alunos da realidade ao trabalhar de forma intencional com problemas vivenciados durante a prática profissional, considerando seus conhecimentos prévios, sem dicotomia entre teoria e prática.

No decorrer da metodologia da ABP ocorrem alterações nos papéis dos atores no cenário educacional - o professor deixa de ser mero transmissor de conhecimento, e assume o papel de orientador do ensino e aprendizagem, favorecendo a autonomia e estimulando o pensamento crítico do estudan$\mathrm{te}^{(5)}$. Os alunos são instigados a assumir crescente responsabilidade perante a própria formação, e com a mediação do tutor, passam a autogerenciar seu processo de aprendizagem e de construção do conhecimento, que ocorre de forma contínua, autônoma e crítica, ou seja, ao longo da vida. Essas mudanças revelam diferentes escopos para a educação, que deixa de ser estritamente técnica/mecânica e se compõe de finalidades política, estética, de inovação e evolução da humanidade.

O processo tutorial além de assegurar a importância dos saberes prévios dos alunos, torna-os capazes de manipular, de forma independente, materiais de apoio como livros, artigos, internet, equipamentos, entre outros, em dosagens que ultrapassam os conteúdos estipulados nos currículos, ou seja, constroem seus próprios caminhos para o conhecimento ${ }^{(6)}$.

Isso é altamente desejável, visto que a realidade que nos circunda, para qual voltamos nossas atitudes e conhecimentos, é, simultaneamente, passível de separação e inseparável. Podemos isolar os elementos que a constitui, entretanto, cada vez mais percebemos que eles estão ligados uns aos outros. O pensamento complexo nos impulsiona a visualizar que as coisas, mesmo separadas - são ligadas, e que essas mesmas coisas ligadas, são igualmente em suas formas, distintas ${ }^{(7)}$.

Assim é o conhecimento, sua (re)construção é um processo dinâmico e que prossegue ao longo da vida. Aos indivíduos que atuam profissionalmente em áreas específicas, como a Enfermagem, faz-se necessário conciliar um conhecimento geral e suficientemente amplo, com níveis adequados de especialização ${ }^{(6)}$ para que assim, emergir para a realidade, o conhecimento pertinente.

Faz-se "extremante importante examinar o que liga as coisas separadas, sempre com o propósito de religá-las". Assim, necessitamos conceber a ética da religação e pensar sobre as formas de organização que reúne os diferentes elementos, pois "religar quer dizer não apenas estabelecer uma conexão complementar, mas estabelecer uma conexão que faça um ciclo completo"(7).

Por ser a aprendizagem um fenômeno interpretativo da realidade, implica um ato contínuo de construção, desconstrução e reconstrução dos saberes ${ }^{(8-9)}$. A ABP com o esquema de tutoria visa fazer com que os alunos saibam aprender e sintam-se desafiados a aplicar suas descobertas em prática. Partindo dessas características, essa nova concepção sobre aprendizagem incita o que no pensamento complexo ${ }^{(10)}$ é reconhecido por "reforma das mentes", que ocorre ao projetar o foco mais intenso sobre as "cabeças bem feitas" em contraposição às "cabeças bem cheias". "Uma cabeça bem feita significa que, em vez de acumular o saber, é mais importante dispor ao mesmo tempo de uma aptidão geral para colocar e tratar os problemas e princípios organizadores que permitam ligar os saberes e lhe dar sentido"(8).

Objetivou-se com este estudo analisar como a ABP promove o desenvolvimento da autonomia do aluno no processo de aprender a aprender.

\section{METODOLOGIA}

Estudo exploratório de cunho qualitativo, no qual se utilizou a Bricolagem ${ }^{(11)}$ como método. A Bricolagem propõe um esquema aberto que visa romper com a monológica de se fazer pesquisa, ou seja, combater o reducionismo. Ela amplia o foco possibilitando a utilização de uma variedade de métodos, instrumentos e referenciais teóricos permitindo que o pesquisador possa compor diversas interpretações.

Desenvolvida em uma universidade pública da região Centro-Oeste, durante o período de estágio docência do programa de pós-graduação em nível de mestrado, a investigação teve como sujeitos os tutores e alunos da disciplina de Introdução ao Gerenciamento em Saúde, ministrada no quarto semestre do curso. Ao todo, somaram 16 (dezesseis) acadêmicos matriculados na referida disciplina; e 2 (dois) professores/tutores que operacionalizaram a metodologia da ABP.

Para a coleta dos dados na perspectiva da Bricolagem, e objetivando compreender todos os complexos elementos envolvidos no cenário da utilização da $\mathrm{ABP}$, foram adotados diversos instrumentos e técnicas de pesquisas, na intenção de captar, com maior abrangência, o fenômeno investigado. A Bricolagem amparou a necessária combinação entre as técnicas de observação participante, entrevista semiestruturada, análise de registros dos alunos em portfólios, fichas de avaliação e de gravação em áudio dos diálogos nas tutorias.

Como estratégia para análise dos dados, na condição de pesquisadoras bricoulers ${ }^{(11)}$, reunimos os diversos elementos que constituíam o fenômeno, na intenção de atribuir-lhes sentido interpretativo, aqui entendido como a "busca pelo 
sentido das falas e das ações" com a finalidade de se alcançar compreensão $^{(12)}$.

A Bricolagem utiliza, para o início da interpretação, o texto como porta de entrada, denominado POETA. Ele funciona como o elemento central para a rede de entretecimento na análise. Um POETA pode ser "qualquer coisa que tenha ou que produza sentido - uma imagem, um livro, uma fotografia, uma teoria"(9). Nesta pesquisa nossos POETAs traduziram-se nos materiais advindos das estratégias de coleta de dados, ou seja: entrevistas com tutores da disciplina, observação participante das sessões tutoriais, gravações em áudio das tutorias, análise de registros em portfólios realizados pelos alunos, e ainda de instrumentos de avaliação.

A análise dos dados seguiu estratégias de interpretação adotadas pelas autoras, percorrendo as seguintes etapas: 1) Leituras iniciais; 2) Leitura aprofundada; 3) Construção de mapas de significados; 4) Articulação dos mapas; 5) Religação dos sentidos e significados, e elaboração das categorias empíricas. Tais categorias foram analisadas à luz do pensamento complexo de Edgar Morin e da pedagogia libertadora em Freire.

Os preceitos estabelecidos na resolução 196/96 foram respeitados, o projeto aprovado pelo Comitê de Ética em Pesquisa, sob n 796/CEP/HUJM, e o Termo de Consentimento Livre e Esclarecido aplicado a todos os participantes.

\section{RESULTADOS E DISCUSSÃO}

A ABP proporciona aos acadêmicos que dela participam, diferentes oportunidades para o desenvolvimento de sua autonomia, assim como formas diversas de lidar com o conhecimento. Percebemos que com a ABP, os alunos aprendem de forma autônoma e colaborativa, constroem e reconstroem seu conhecimento mediados pelas atividades recorrentes do método e pelas novas funções que tanto alunos quanto tutores precisam exercer.

Organizamos os resultados com a finalidade de melhor explicitar os momentos nos quais os alunos (re)estruturam seus conhecimentos, munidos pela autonomia proporcionada pela metodologia da $A B$, e exercitam, assim, o aprender a aprender. Nessa intenção, apresentamos a seguir as categorias: a (re)construção do conhecimento a partir dos saberes prévios; a (re)construção do conhecimento a partir do exercício da teorização; a (re)construção do conhecimento possibilitada pela religação dos saberes; e a autonomia envolvida na busca pelo conhecimento pertinente.

\section{A (re)construção do conhecimento a partir dos saberes e experiências prévias}

Uma das mudanças relacionadas ao conhecimento constatada neste estudo foi a possibilidade do saber em enfermagem ser (re)construído de forma individual e coletiva no grupo tutorial. Esse processo iniciou-se com o reconhecimento da importância dos saberes e experiências prévias dos alunos, oriundos de base empírica e adquiridos por meio de vivências, e do contato com a realidade. Estes conhecimentos foram partilhados entre os colegas durante as discussões que percorreram as etapas da identificação dos termos desconhecidos; definição dos problemas; brainstorming; e sistematização das hipóteses; que correspondem aos primeiros 4 passos da operacionalização da $\mathrm{ABP}$.

Esse processo possibilitou a troca de informações entre os alunos, que passaram a se comunicar melhor, argumentar e defender opiniões, analisar criticamente a veracidade e a aplicabilidade dos saberes à realidade tratada no caso, julgando em consenso, se os conhecimentos já obtidos e debatidos pelo grupo são satisfatórios para a compreensão da situação-problema. Desse modo, o saber deixa de ser exclusivamente concebido pelo professor, pois os alunos percebem que também é possível aprender com os colegas, assim como as informações prévias e as experiências/vivências que já possuem, podem ser tão valiosos quanto resultados de investigação científica.

Percebi que cada um pode contribuir com o grupo através de experiências antes vividas. [...] Na medida em surgiam as dúvidas sobre determinados assuntos ou termos, íamos discorrendo nosso entendimento a respeito do mesmo. (Portfólio 2)

Então essa nossa parte do diálogo aqui é importante, porque eu posso usar o que eu sei, o nosso conhecimento prévio, porque ele também é importante tá? Então tentem trazer tudo o que sabem [...]. (Áudio Tutoria grupo 1)

Atualmente, o caráter autobiográfico e autorreferencial do conhecimento, é plenamente assumido ${ }^{(13)}$. A realidade complexa exige cada vez mais, o entrelaçamento entre os saberes pessoais e o que é estudado em sala de aula, ou seja, um conhecimento que seja íntimo, que permita a união entre o sujeito e objeto, considerando as subjetividades e percepções implicadas.

Faz-se de extrema importância considerar os saberes do senso comum, visto que são eles que orientam a maior parte de nossas ações como seres humanos, e é pelo uso dos mesmos, que damos sentido a nossas vidas ${ }^{(13)}$. Portanto, os conhecimentos prévios dos educandos necessitam ser considerados durante as atividades acadêmicas, pois na medida em que são ativados, ocorre a significação do novo saber estruturado ao contexto em que está sendo estudado ${ }^{(14)}$.

Os saberes de senso comum e os científicos, quando interpenetrados um pelo outro, dialogam entre si, e originam uma nova racionalidade na qual o processo dialógico configura a transformação do senso comum em ciência e vice-versa ${ }^{(13)}$.

É responsabilidade, tanto da escola quanto do educador, considerar os saberes dos educandos, e também as formas como são organizados, pois são "socialmente construídos na prática comunitária", e fazem parte de seu cotidiano e de suas vidas. $\mathrm{O}$ ensino da realidade concreta associada aos conteúdos ministrados nas disciplinas é proposto com o intuito de estabelecer uma "intimidade entre os saberes curriculares fundamentais aos alunos e a experiência social deles como indivíduos"(7), portanto, o professor precisa respeitar o saber de pura experiência do aluno, bem como estimular a capacidade criadora e indagadora do educando. Nessa perspectiva, este é um papel ético do professor, fazer com que o aluno pense e reflita sobre sua realidade, para assim se tornar cada vez mais liberto. 
Percebemos que a proposta da ABP vai ao encontro deste importantíssimo aspecto, considerado na pedagogia libertadora de Freire. Ao trabalhar com casos fictícios que retratam a realidade, o aprendizado dos alunos torna-se significativo.

Discutir com os colegas fortalece o trabalho em equipe e retrata melhor a realidade. (Portfólio 6)

Uma aluna relata sobre experiência de estágio voluntário que fez no hospital de sua cidade, o que desperta a atenção dos demais alunos, antes dispersos. (Relatório Observadora 2)

[...] lá no sétimo semestre eles falam assim que não viram, não sabem [...] eles não sabem o que é gerenciamento. Por quê? Porque eles não significaram aquilo, eles não conseguiram enxergar aquilo numa situação concreta. Então pra mim faz toda diferença quando você traz [...] a situação-problema. (Entrevista Tutora 2)

A ABP como estratégia de ensino amparada na aprendizagem pela descoberta e aprendizagem significativa, valoriza o princípio do aprender a aprender. Todo conhecimento para ser significativo necessita estabelecer relação com saberes prévios dos alunos, favorecendo sua autonomia para assimilar conhecimento empírico e cientifico em um único contexto. $\mathrm{Na}$ aprendizagem significativa o aluno atua como protagonista no processo de construção do próprio conhecimento(2).

A metodologia da ABP proporciona autonomia para que o próprio aluno crie sua rede de entrelaçamento de saberes prévios com novas estruturas cognitivas. Podemos afirmar neste sentido, que o aprendizado é um fenômeno complexo e não se concretiza pela soma ou acréscimos de conhecimentos, mas sim, pelas novas estruturas de conexão que cada sujeito é capaz de construir para $\mathrm{si}^{(2)}$.

Nessa perspectiva, a aprendizagem ocorre verdadeiramente quando o sujeito consegue integrar a informação que lhe chega no formato mais abrangente, com a informação que já possui ${ }^{(13)}$. Considerando este aspecto pode-se falar em aprendizagem como construção de conhecimento, pois caso contrário, as informações podem estar somente se acumulando de forma paralela, transformando-se tão somente em respostas corretas, que são facilmente perdidas e esquecidas.

\section{A (re)construção do conhecimento a partir do exercício da teorização}

A (re)construção do conhecimento também foi influenciada pelo processo de teorização (passo 6) da ABP. Os alunos, ao consumirem resultados de pesquisas com vistas a preencher as lacunas de conhecimento, compreenderem e darem resolutividade ao caso, puderam constatar que possuíam concepções equivocadas sobre temas debatidos no grupo tutorial, e assim reformular suas ideias mediante identificação do equívoco.

Muitas coisas que eu pensava saber quando fui pesquisar não era como eu pensava, outras eu nem imaginava que existiam. [...] Agora que estou com a pesquisa pronta, estou ansiosa pela próxima etapa. (Portfólio 11)

De imediato fiquei perplexa por ter ciência do quão pobre era meu vocabulário. Vários termos que estavam nos textos me eram desconhecidos. O interessante foi ter a oportunidade de conhecer terminologias novas. (Portfólio 12)

A teorização em bases científicas, além de proporcionar a oportunidade para o consumo de resultados de pesquisas, também permitiu o exercício de postura crítica sobre a leitura do material, analisando sob quais formas essas pesquisas poderiam ser empregadas na problemática do caso. $\mathrm{O}$ ato de pesquisar, assim como o de consumir resultados de pesquisa é considerado de extrema importância no desenvolvimento da autonomia e consequente liberdade do aluno. "Não há ensino sem pesquisa e pesquisa sem ensino"(15), a pesquisa visa satisfazer as indagações, ou seja, conhecimentos que necessitam ser aprimorados ou até mesmo (re)avivados, a apreensão de novos saberes auxilia nas intervenções que podem influenciar mudanças na realidade do indivíduo.

A APB enquanto método possibilita que o aluno busque pelo conhecimento de forma autônoma permitindo-o obter renovações contínuas de informações para que alcance êxitos cognitivos durante a vida acadêmica, e se torne capaz de desenvolver destrezas, atitudes, valores e competências que irão subsidiar sua prática profissional ${ }^{(6)}$.

Assim, a busca e o contato com a produção de conhecimentos disponibilizados em fontes idôneas, auxiliou a construção não só da capacidade cognitiva do aluno, como também seu poder de análise crítica. A aprendizagem reflexiva considera a importância das respostas cognitivas, entretanto, os pensamentos e os sentimentos também devem ser relevados, pois estão envolvidos em uma rede de caminhos altamente complexos ${ }^{(1)}$.

Hoje (referindo-se após a teorização) a discussão foi bem proveitosa e interessante, analisei a situação diferente e com um olhar mais compreensivo da situação, até porque busquei conceitos que não estavam no meu entendimento. (Portfólio 5)

Olha só, baseados nos que vocês trouxeram (teorização), o que vocês acham que Amanda (enfermeira do caso fictício) deveria fazer? (Áudio Tutoria Grupo 1)

Na percepção de alunos e tutores, a busca pelo saber é um movimento contínuo, e as atualizações técnicas e cognitivas precisam ser realizadas ao longo de toda a vida profissional. Portanto, o processo de aprender a aprender se firmou pelo fato dos alunos, para além de compreenderem a constante necessidade de atualização, tomarem consciência acerca de 'como' e 'onde' buscar o conhecimento aplicável para a situação específica sob estudo.

O segundo ponto seria aprendizado ao longo da vida, que eles estão aprendendo a aprender eles não tem uma ... algo que a gente possa dizer que tá pronto e acabado né? 


\section{[...]. (Entrevista Tutora 1)}

Embora a autonomia do aluno como construtor do conhecimento seja algo resguardado durante a metodologia da ABP, esse processo é viabilizado pela consequente liberdade do aluno, ou seja, é um processo recursivo, a existência de uma depende do desenvolvimento da outra. A liberdade envolve um alto grau de subjetividade e é definida "pelo conjunto de possibilidades de invenção, de escolha, de decisão, de apropriação de acasos e determinismos", assim, primeiramente ela "define-se pelo conhecimento; em seguida, "pela possibilidade do sujeito agir em função desse conhecimento"(16).

Nesta mesma perspectiva, a educação é o que permite a libertação do sujeito. Para tornar-se liberto, é preciso necessariamente a prática da autocrítica, embebida pela autoconsciência do próprio inacabamento como ser humano ${ }^{(15)}$.

O exercício da autocrítica estimulado pela metodologia da $A B P$, fez com que os alunos refletissem sobre a forma como cumpriram suas investigações teóricas. Os resultados desse exercício apontaram tanto para a necessidade de aprimorar as estratégias de busca, levando a perceber necessidade de melhorar a execução da atividade, como também, para a satisfação com a busca bibliográfica realizada, e até entusiasmo em partilhar com colegas os resultados obtidos.

Não pesquisei como deveria, por isso me senti um pouco apreensiva, reconheço que poderia ter feito mais [...]. (Portfólio 5)

Não foi difícil encontrar textos e artigos que respondessem as questões. Foi um exercício de pesquisa e leitura prazeroso. (Portfólio 14)

Aspecto relevante no processo de aprender a aprender possibilitado pela $A B P$, é a busca e a teorização por conceitos do problema fictício ${ }^{(17)}$. Nesta etapa, os alunos são estimulados a consultar livros, periódicos, jornais, revistas, internet, profissionais e experts sobre os temas. Cabe ao tutor nesta etapa, o importante papel de incentivo, pois se a estratégia de teorização for falha, os alunos podem perder a autoconfiança e se sentirem desestimulados com a metodologia.

Essas reflexões críticas sobre a própria atuação envolvem a constante exploração dos sentimentos que compõe uma parte importante sobre as experiências vividas, formação dos pensamentos e sensações da experiência particular. "Os sentimentos influenciam a motivação para agir e, consequentemente, no processo cognitivo"(1).

Assim o tutor necessita estar atento às expressões de sentimentos dos alunos durante a metodologia, pois como mediador do processo de aprendizagem, possui importante missão de auxiliar os alunos a vencer suas barreiras, e a alcançar êxito.

\section{A (re)construção do conhecimento possibilitada pela reli- gação dos saberes}

Durante vários momentos das sessões tutoriais, mediados pelo tutor ou por iniciativa própria, os alunos associaram vários dos temas tratados na disciplina de gerenciamento com outras disciplinas do curso de enfermagem, ou seja, realizaram interdisciplinarização. A associação entre os temas emergiam de experiências vividas durante a formação acadêmica no atual semestre e em anteriores, tanto nas práticas curriculares, quanto em disciplinas ministradas por outros professores.

Percebi que o gerenciamento que o enfermeiro faz em seu trabalho está baseado em conceitos da administração, o que revela a importância de lançar mão em outras áreas de conhecimento e não ter o foco limitado. (Portfólio 9)

[...] foi possível ver que a administração em enfermagem requer o conhecimento de teorias da administração; de filosofia do serviço de enfermagem; das políticas de saúde; da legislação e muitas outras teorias para o funcionamento total dessa administração, sendo portanto importante para nos enfermeiros expandir a leitura para áreas além da saúde. (Portfólio 14)

(referindo-se a teorização) Resolução de conflitos eu coloquei junto com o conceito de liderança [...] A partir desse conceito de líder, de uma forma de líder, é que ele vai buscar encontrar os meios para estar resolvendo os conflitos [...]. (Áudio Tutoria Grupo 1 - Aluna)

As ideias morinianas aplicadas à educação, considerando o contexto cognitivo, "privilegiam a religação dos saberes e a prática transdisciplinar". Existe uma real necessidade de transitar pelas diversas áreas do conhecimento, de forma a promover um diálogo entre as ciências e as formas epistemológicas de pensar ${ }^{(18)}$.

A atual forma como os currículos de enfermagem se encontram dispostos, segue a lógica dispersa e parcelada advinda do desenvolvimento técnico - cientifico do século XIX. "A educação deve levar em conta a complexidade do real, evitando conceber as disciplinas do currículo de forma isolada"(18).

Assim, ao analisarmos a composição do projeto pedagógico do Curso de Graduação em Enfermagem, percebemos que o mesmo detalha a grade curricular, explicitando as disciplinas que o compõe, ementa, carga horária, competências requeridas e bibliografia a ser utilizada. Essas disciplinas se combinam por áreas de concentração e formam os blocos ou semestres que compõem o Curso. Da mesma forma, a composição do quadro docente atuante na faculdade, subdivide-se entre grupos de trabalho combinados por área de atuação: Enfermagem Fundamental; Saúde da Criança e do Adolescente; Saúde Sexual e Reprodutiva; Saúde do Adulto; Saúde Mental; Administração em Enfermagem; Estágio curricular.

Em estudo recente ${ }^{(19)}$ em que foi analisada a gestão do trabalho docente na referida instituição, constatou-se que um dos objetivos estabelecidos no plano pedagógico e pelos componentes dos cargos de gestão é a integração entre as áreas de concentração que compõe a grade curricular do curso, como tentativa de evitar o parcelamento/fragmentação entre os saberes. Entretanto, apesar de constar no PPP a intencionalidade da integração, o desenvolvimento do trabalho docente na realidade estudada, satisfaz esse objetivo a título operacional, não permitindo ainda, a necessária transdisciplinaridade. 
A forma predominante de se fazer educação, que persiste no sistema disciplinar, desconsidera a urgência da reforma do pensamento e dificulta os processos de desenvolvimento da autonomia e senso crítico, imprescindíveis para a emancipação do sujeito. Assim, o currículo "fragmentado em disciplinas perde a visão de conjunto, dificulta o diálogo entre os saberes e causa desinteresse dos estudantes pelos seus conteúdos"(18).

Nesse cenário, a complexidade emerge não como solução para os problemas do mundo, mas como uma alternativa, pois no âmbito educacional visa contemplar um "novo contexto cognitivo que privilegia a religação dos saberes e a prática transdis-

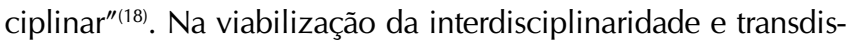
ciplinaridade, a ABP se mostra como uma potente metodologia, capaz de subsidiar a composição de um currículo integrado.

$\mathrm{Na}$ abordagem complexa, o conhecimento fragmentado e constituído de forma isolada é insuficiente, "visto que e preciso situá-los em seu contexto para que adquiram sentido". Desta forma, a interdisciplinaridade na Enfermagem/Saúde, incita a "necessidade de religação dos saberes para permitir a relação da parte no todo e do todo na parte"(9).

\section{A autonomia do educando na (re)construção do conheci- mento pertinente}

O educador, para desenvolver a autonomia de seus alunos, precisa realizar atividades que estimulem a tomada de decisão e a responsabilidade pela própria formação, para que eles aprendam a decidir com liberdade ${ }^{(20)}$ assumindo todas as consequências desse ato, portanto, essa autonomia deve abranger a liberdade pela busca do conhecimento pertinente.

Na metodologia da ABP, as situações-problemas são elaboradas pelos professores e visam atender uma série de temas estabelecidos nos programas curriculares dos cursos. Neste caso em particular, isso não se deu de modo diferente, ou seja, a situação-problema elaborada percorreu pelos temas estabelecidos no conteúdo disciplinar. Entretanto, mesmo com o caso trazendo temas específicos, os alunos aprenderam de forma independente a buscar o conhecimento pertinente, aquele passível de ser aplicado à prática, neste particular, à situação problema utilizada.

O conhecimento pertinente para a educação da era planetária necessita resgatar "o contexto, o global; o multidimensional e o complexo"(10), assim o contexto necessita ser considerado com a finalidade de dar sentido à informação, o global reúne as diversas partes ligadas ao contexto de forma inter-retroativa, e o aspecto multidimensional visa captar todas as dimensões/facetas a serem consideradas, enfrentando assim, a complexidade dos elementos da realidade que são "tecidos juntos".

Nesta atividade realizamos um debate, ou, melhor dizendo, discussões pertinentes aos termos utilizados no texto. (Portfólio 2)

Hoje fizemos a problematização e discussão do caso, levantamos questões pertinentes a ele e a disciplina. (Portfólio 7)

Dessa maneira, os problemas expostos no caso fictício do método $\mathrm{ABP}$, não foram analisados ou tratados de forma reducionista ou isolada/fragmentada. Por mais que objetivos e metas tenham sido estabelecidos com vistas a dar respostas e resolutividade ao caso, podemos afirmar que as questões de aprendizagem (passo 5) foram elaboradas considerando as conexões entre os temas, e com vistas a satisfazer a problemática geral do caso.

Destacamos também que, durante a metodologia, os temas não foram aprofundados teoricamente, pois a metodologia prioriza o manejo do conhecimento pertinente necessário para cada situação. Neste ponto, ressaltamos que a ABP visa romper com o 'depósito conteudista' da 'educação bancária'(15), segundo a qual é preciso esgotar todo o conhecimento.

A lógica instaurada pela metodologia ativa abre a possibilidade para que os alunos tenham acesso à informação de forma autônoma, e que possam articulá-la ou aplicá-la nas circunstancias em que o problema se apresentar. Essa decisão parte dos próprios alunos ao analisarem criticamente sobre a necessidade de busca pelo conhecimento. Na perspectiva complexa, "o conhecimento completo é inatingível. Esta forma de pensar comporta o reconhecimento de um principio de não completude e de incertezas" ${ }^{\prime \prime)}$.

Portanto, a viabilização da autonomia pela ABP, faz com que os alunos estejam preparados para enfrentar situações problema da realidade, considerando a multidimensionalidade dos fenômenos, construindo conhecimento pertinente, ou seja, aquele que permite manejar as informações necessárias à compreensão e resolução do caso.

\section{CONSIDERAÇÕES FINAIS}

A ABP como metodologia de ensino centrada no aluno, visa problematizar casos da realidade para significar os conteúdos tratados nos currículos, bem como promover o desenvolvimento da autonomia do educando perante seu processo de formação.

A análise deste estudo evidenciou que os alunos e tutores percebem diferentes formas de lidar com o conhecimento e passam a exercer novos papéis no processo ensino-aprendizagem. Os alunos se reconhecem como responsáveis pelo próprio aprendizado e gozam de autonomia na (re)construção do conhecimento. Verificamos que os acadêmicos tornam-se aptos a interligar saberes e experiências prévias, àqueles disponibilizados no meio científico. Desenvolvem ainda a habilidade para religar saberes, antes fragmentados e desconexos, e para autonomia na busca pelo conhecimento pertinente.

A ABP enquanto metodologia prioriza a aprendizagem significativa ao possibilitar articulação da realidade ao que está sendo estudado, resgatando a complexidade e multidimensionalidade dos elementos envolvidos no contexto.

O exercício da teorização estimula o consumo de resultados de pesquisa e incita a atualização continua, pois o conhecimento transcende a história com movimento em espiral, sempre renovando e reconstruindo concepções. Além disso, ocorre o despertar do senso crítico do aluno sobre os materiais científicos com os quais passa a ter um contato constante. Essa aprendizagem reflexiva é cada vez mais valorizada durante a prática educativa, e faz com que os alunos se tornem sujeitos éticos-políticos, com postura emancipada frente as forças opressoras. 


\section{REFERÊNCIAS}

1. Burgatti JC, Leonello VM, Bracialli AD, Olivieria MACl. Estratégias pedagógicas para o desenvolvimento da competência ético-política na formação inicial em enfermagem. Rev Bras Enferm. 2013;66(2):282-6.

2. Cyrino EG, Toralles-Pereira ML. Trabalhando com estratégias de ensino-aprendizado por descoberta na área da saúde: a problematização e a aprendizagem baseada em problemas. Cad Saúde Pública. 2004;20(3):780-8.

3. Mitre SM, Siqueira-Batista R, Moreira $T$, Morais-Pinto NM, Meirelles CAB, Pinto-Porto $C$, et al. Metodologias ativas de ensino-aprendizagem na formação profissional em saúde: debates atuais. Ciênc Saúde Coletiva. 2008;13(2):2133-44.

4. Waterkemper R, Prado ML. Estratégias de ensino-aprendizagem em cursos de graduação em Enfermagem. Av Enferm [Internet]. 2011 [acesso em 31 de julho de 2013];29(2):234-46. Disponível em: http://bases.bireme. br/cgi-bin/wxislind.exe/iah/online/?lsisScript = iah/iah.xis $\& \mathrm{src}=$ google \&base $=$ LILACS \&lang $=p \&$ nextAction $=$ lnk \&exprSearch $=635409$ \&indexSearch $=$ ID

5. Paranhos VD, Mendes MMR. Currículo por competência e metodologia ativa: percepção de estudantes de enfermagem. Rev Latinoam Enferm. 2010;18(1):109-15.

6. Calle Marquez MG, Saavedra Guzman LR. La tutoría como mediación para el desarrollo autónomo del estudiante. Tabula Rasa. 2009;(11):309-28.

7. Morin E. O método 6: ética. Porto Alegre (RS): Sulina; 2011.

8. Bragagnolo Frison ML. Tutoria entre estudantes: uma proposta de trabalho que prioriza a aprendizagem. Rev Port Educação. 2012;25(2):217-40.

9. Santos SSC, Hammerschmidt KSA. A complexidade e a religação de saberes interdisciplinares: contribuição do pensamento de Edgar Morin. Rev Bras Enferm. 2012;65(4):561-5.
10. Morin E. Os sete saberes necessários à educação do futuro. 2. ed. São Paulo (SP): Cortez; 2011.

11. Kincheloe J. Pesquisa em Educação: conceituando a bricolagem. Porto Alegre (RS): Artmed; 2007.

12. Ribeiro MRR. Avaliação educacional em enfermagem na perspectiva da complexidade: a trama das interações e estratégias de (sobre)vivências [tese]. São Paulo (SP): Universidade de São Paulo; 2009.

13. Santos BS. Um discurso sobre as ciências. 7. ed. São Paulo (SP): Cortez; 2010.

14. Almeida LS. Facilitar a aprendizagem: ajudar aos alunos a aprender e a pensar. Psicol Esc Educ [Internet]. 2002 [acesso em 31 de julho de 2013];6(2):155-65. Disponível em: http://pepsic.bvsalud.org/scielo.php?pid=S1413$-85572002000200006 \&$ script $=$ sci_abstract

15. Freire P. Pedagogia da Autonomia: saberes necessários a pratica educativa. São Paulo (SP): Paz e Terra; 2011.

16. Fortin R. Compreender a Complexidade. Introdução ao Método de Edgar Morin. Lisboa: Instituto Piaget; 2005.

17. Escrivão Filho E, Ribeiro LRC. Inovando no ensino de administração: uma experiência com a aprendizagem baseada em problemas (PBL). Cad EBAPE.BR. 2008;6 ( ${ }^{\circ}$. esp.):1-9.

18. Almeida C, Petraglia I, organizadores. Estudos de complexidade. São Paulo (SP): Xamã; 2006.

19. Campos LRG, Ribeiro MRR. Gestão do trabalho docente em uma faculdade de enfermagem: percepção de gestores [graduação]. Nova Xavantina (MT): Universidade Federal de Mato Grosso /UAB; 2012.

20. Silva APSS, Pedro E R. Autonomia no processo de construção do conhecimento de alunos de enfermagem: o chat educacional como ferramenta de ensino. Rev Latinoam Enferm. 2010; 18(2):210-6. 